\title{
Connecting Analytics and Curriculum Design: Process and Outcomes of Building a Tool to Browse Data Relevant to Course Designers
}

\author{
Robert L. Dunbar, Molly J. Dingel, Xavier Prat-Resina \\ Center for Learning Innovation, University of Minnesota Rochester, USA \\ dunb0011@r.umn.edu
}

\begin{abstract}
The disconnect between data collection and analysis across academic and administrative units within institutions of higher education makes it challenging to incorporate diverse data into curricular design. Understanding the factors related to student retention and success is unlikely to occur by focusing on only one unit at a time. By promoting course design informed by data from diverse units, we are more likely to understand important connections that could encourage more effective and holistic change. Facilitating evidence-based course design should begin with a faculty-driven process to identify how best to explore data across units for integration into the traditional course/curricular design. Our paper describes how data from institutional, learning, and what we call "developmental" analytics can be incorporated into course and curricular design by using a purposefully built analysis tool that permits the exploration of data relevant to course/curriculum design. This Browser of Student and Course Objects (BoSCO) is being built in a faculty-driven process and can be used as a bridge between the analytics space and the course/curriculum design environments, therefore encouraging faculty to use analytics for course and curricular design.
\end{abstract}

Keywords: Curricular design, analytics, data analysis, analytics tool

\section{INTRODUCTION}

Day after day, day after day,

We stuck, nor breath nor motion;

As idle as a painted ship

Upon a painted ocean.

Water, water, every where,

And all the boards did shrink;

Water, water, every where,

Nor any drop to drink.

-Samuel Taylor Coleridge,

"The Rime of the Ancient Mariner"

There has been a clear call-to-action to improve the state of education at the undergraduate level (Boyer Commission, 1998; National Research Council, 1996; National Science Foundation, 1996; 
(2014). Connecting Analytics and Curriculum Design: Process and Outcomes of Building a Tool to Browse Data Relevant to Course Designers. Journal of Learning Analytics, 1 (3), 223-243.

Executive Office, 2009). Many departments face significant pressure from accreditors, administrators, and, for public institutions, state legislators, to detail student learning within departments, majors, or programs (U.S. Department of Education, 2000). Substantial resources and effort have led to the development and implementation of a striking array of evidence-based practices within classrooms, curricula, and campuses. However, the majority of these initiatives have been developed and implemented independently with little intentional communication among disciplines or across academic and administrative units (Labov, Singer, George, Schweingruber, \& Hilton, 2009; Henderson, Beach, \& Finkelstein, 2011). Given that these independent efforts have led to moderate success (Boyer Commission, 1998; Handelsman, Miller, \& Pfund, 2007), it seems reasonable to hypothesize that a larger effect on education might be achieved with a more synergistic approach based on a concerted and collaborative effort on the part of educators, researchers, staff, and administration. Indeed, the most effective approach to changing undergraduate instruction involves designing long-term strategies that are compatible with the complex and dynamic nature of colleges and universities (Henderson et al., 2011). At the same time, however, it is challenging to find a practical, systematic way to connect these individual, separate practices into unified processes. Such processes have the potential to promote student retention and success by permitting the exploration of data immediately relevant to designers of individual courses and also to groups or individuals responsible for higher-level programmatic curricular design and evaluation.

Solutions to expansive problems like student retention and success are unlikely to be reached by independently adjusting factors in separate units of an institution. To begin to facilitate reaching the goals of increased student retention and success on a campus or a program, we must promote it in the classroom through course design informed by diverse types of data typically collected disparately across an institution. Like water in "The Rime of the Ancient Mariner," data seems to be everywhere but in practice, effectively using that data to inform curricular design presents an enormous challenge. As others (Henderson et al., 2011; Buerck \& Mudigonda, 2014) have shown, top-down approaches to academic analytics or curricular change initiatives are rarely successful. In this paper, we describe a bottom-up approach that we have implemented in an effort to facilitate faculty usage of data in course design. This approach was based on the belief that building programs and courses informed by data requires that the people designing the programs and courses, generally faculty, are part of any effort to gather data, define questions, and design the necessary tools. We also believe that this approach will have a ripple effect radiating from the course level through the program level by providing data not only useful to course designers but also to program designers.

Our approach, which drew heavily from our current understanding of academic analytics, design theory, and the principles of institutional change, began with talking to all faculty within our interdisciplinary department. Through these discussions, it became very clear that faculty wanted to collect and analyze data not typically associated with course learning objectives, but variables typically of interest to those in student development, like student attitudes, curiosity, or self-awareness. As we explain below, the high faculty demand for this type of data suggested to us that the endeavour of academic analytics 
(2014). Connecting Analytics and Curriculum Design: Process and Outcomes of Building a Tool to Browse Data Relevant to Course Designers. Journal of Learning Analytics, 1 (3), 223-243.

might benefit from the inclusion of data from institutional, learning, and what we call "developmental" analytics. Our process, which has to date included one semi-structured focus group, two formal meetings, two surveys, and multiple informal feedback sessions, also revealed that faculty would be more likely to use analytics tools that permit them to explore the datasets they think are relevant. As a result, a principal outcome of our bottom-up process has been the development of a tool that gives faculty the ability to share and browse datasets related to the areas of institutional, learning, and developmental analytics. It is our hope that use of this tool not only facilitates data-driven course design but also provides a refined lens to inform future research questions related to understanding the relationship between course design and student success and retention.

\section{COURSE AND CURRICULAR DESIGN USING DATA}

Work by others has clearly demonstrated the value of adopting a synergistic view of incorporating diverse types of information when exploring variables related to student retention and success. For example, the research of Tinto (1997) and others (Antonio, 2004; Buckingham Shum \& Ferguson, 2012; Severiens \& Schmidt, 2009) relies heavily on diverse datasets and demonstrates that student involvement and participation in schools are important factors in student retention. In fact, in one study, Tinto (1997) concludes that encouraging greater involvement in academic and social activities positively affects student learning and retention. This study strongly suggests that the practices and policies across an institution are critically interrelated when it comes to the relationship between student retention, academic experiences, and social development and involvement (Tinto, 1997).

Though it presents theoretical and practical challenges, we must move beyond simply knowing that data from a variety of units across an academic institution are important for understanding correlations with student success and retention, to an environment in which the outcome of analyzing these different datasets can be effectively incorporated into course and curriculum design. At a foundational level, this transition requires an understanding of what "analytics" means across the academic and administrative units of an institution, a design framework in which to use data effectively for course design, and tools that permit timely and informative analysis of data relevant to course design. Below we clarify our understanding of each of these requirements as they apply to facilitating evidence-based curricular design.

\subsection{Academic Analytics}

Understanding exactly what the term "analytics" means in academia can be confusing because the terminology is connected to but not always aligned with that used to describe the institutional and course goals being explored with analytics (Siemens \& Long, 2011; Oblinger, 2012a). However, at a general level, we can define analytics as "the use of data, statistical and quantitative methods, and explanatory and predictive models to allow organizations and individuals to gain insights into and act on complex issues" (Oblinger, 2012b, para. 2). "Academic analytics" refers to cases in which analytics are 
(2014). Connecting Analytics and Curriculum Design: Process and Outcomes of Building a Tool to Browse Data Relevant to Course Designers. Journal of Learning Analytics, 1 (3), 223-243.

applied within academic settings and includes two subtypes of applied analytics called "institutional analytics" and "learning analytics." At the institutional/administrative level, analytics is often used to understand factors that relate specifically to helping "run the business of the higher education institution" by attempting to predict student success and retention rates (Oblinger, 2012b, para. 2). The related, but to date conceptually separate term "learning analytics" is best understood as analytics that focus "on students and their learning behaviours, gathering data from course management and student information systems in order to improve student success" (Oblinger, 2012b, para. 2). Both institutional and learning analytics align well with the goals of academic analytics within an institution, as they facilitate understanding of student success and retention from slightly different perspectives (Figure 1).

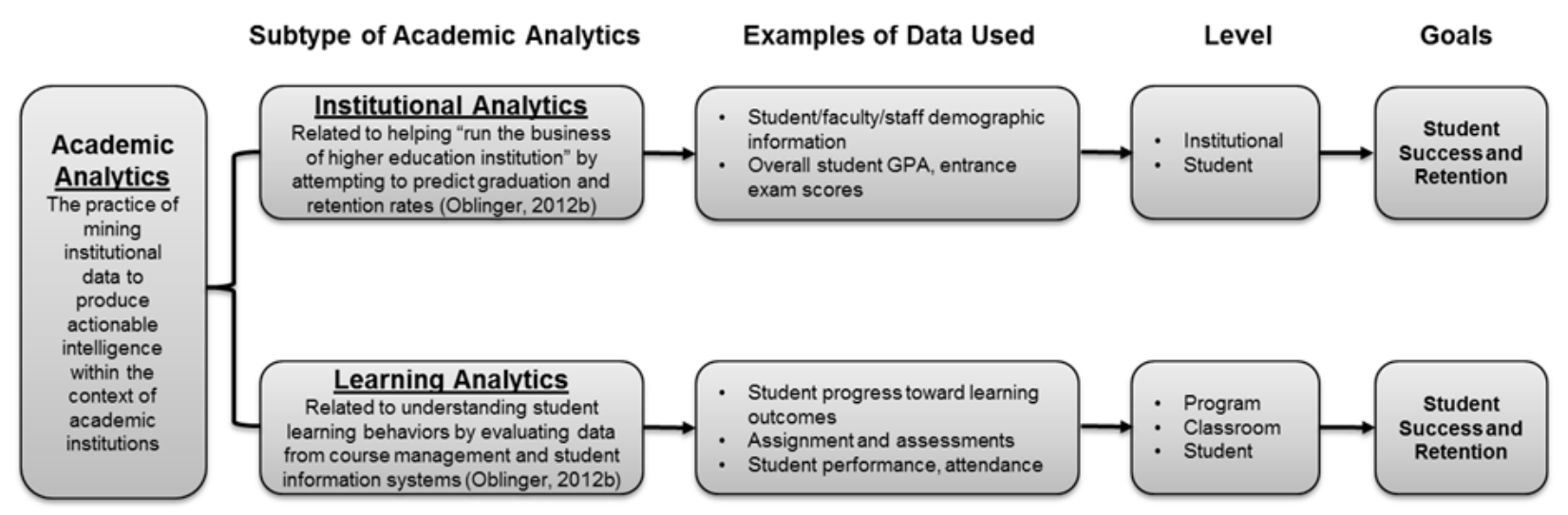

Figure 1. Summary of academic analytics, institutional analytics, and learning analytics.

\subsection{Course Design Model}

Facilitating a strong connection among course design, data collection, and data analysis represents a tremendous opportunity to increase both the efficiency and effectiveness of course and curriculum design in undergraduate education. Information gathered by faculty members using well-designed learning analytics tools would facilitate the use of the available data as part of a modified Analysis, Design, Develop, Implement, and Evaluate (ADDIE) instructional design process (Molenda, 2003). Using this process, an instructor would design, develop, and implement a course, and then analyze data in a rigorous way to assess what worked, what did not, what should be maintained, and what should be modified or discontinued (Figure 2A). However, traditional course design generally deviates from this process, and is best described as a modified ADDIE process in which the design and delivery of courses is mostly (or only) informed by faculty intuition or unstructured observations about how previous courses went. In fact, exploring the "data" in this case is often limited to an instructor's quick perusal of overall grade distribution, reaction to anecdotal evidence, like verbal feedback from students after a class, or visual perception of students' interest during the class. As shown in Figure 2B, the major pathway (large arrow) from "implement" to "design" bypasses "analyze data." Large data sets, in combination with tools and methods that allow for easy analysis of the data, have the potential to allow faculty to add 
(2014). Connecting Analytics and Curriculum Design: Process and Outcomes of Building a Tool to Browse Data Relevant to Course Designers. Journal of Learning Analytics, 1 (3), 223-243.

depth to the evaluation phase of typical instructional design through the analysis of data relevant to curriculum design, which then informs design and delivery (Figure $2 \mathrm{C}$ ). However, as indicated by the presence of the dotted arrow, even the most robust data sets do not completely erase the need for the "art" of teaching. Anecdotal evidence, including informal student feedback or instructor observations of student engagement during class, does and should provide useful clues to instructors in terms of modifying instruction, but should be secondary to more structured and rigorous assessment methods.

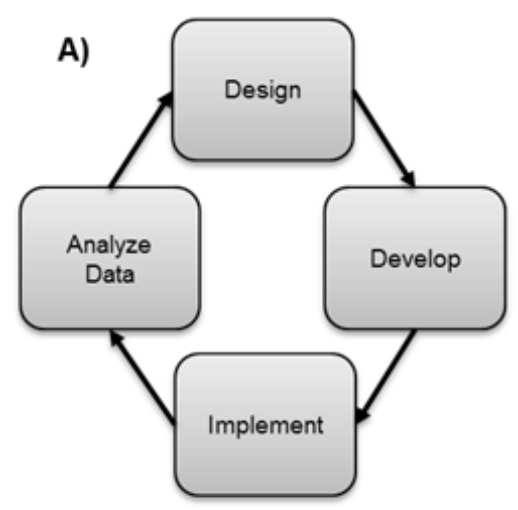

ADDIE In Theory

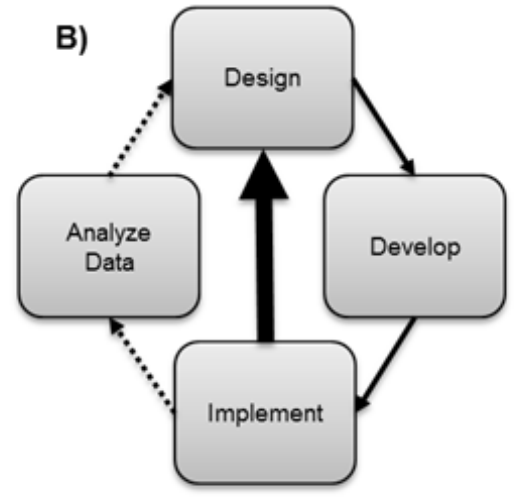

ADDIE Traditionally Applied

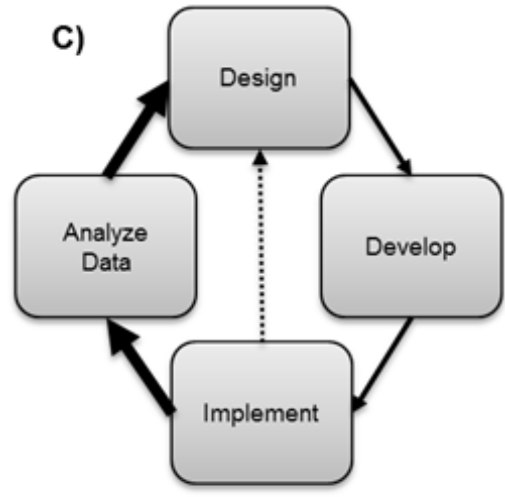

ADDIE Proposed

Figure 2. Schematic of the Analyze, Design, Develop, Implement, and Evaluate (ADDIE) model in theory and as applied in curriculum design.

A) Theoretical ADDIE model. B) Traditional curriculum design strategy with the tendency to bypass rigorous data analysis in the design process as denoted by the large arrow between "Implement" and "Design." C) A modified approach that includes a more intentional use of data in the design process as denoted by larger arrows between "Implement," "Analyze Data," and "Design."

\subsection{Existing Tools}

In order to put data back into the ADDIE process, many groups are working to design and implement learning analytics tools for e-learning (c.f., Ali, Hatala, Gašević, \& Jovanović, 2012; Buerck \& Mudigonda, 2014; Ferguson, 2012; Macfadyen \& Dawson, 2010). These tools and strategies have made some gains in helping faculty visualize student access and activities in Learning Course Management Systems, especially for online courses (Ali et al., 2012; Ferguson, 2012). However, the results from these programs also serve to highlight two major problems faced by the emerging field of learning analytics. Morris, Finnegan, and Wu (2005) and Macfadyen and Dawson (2010) both found that their variables, which similarly include visits to an online course website and time on task, explained only about 30 percent of variance in students' final grades. As Morris et al. admit, their study confirms the obvious: that "students who are more engaged with the content and discussions in an online course will persist and complete successfully" (2005, p. 229). This analysis might be perceived as a first step in learning analytics, and is therefore necessary and meaningful, but complete analysis requires researchers to move beyond this 
(2014). Connecting Analytics and Curriculum Design: Process and Outcomes of Building a Tool to Browse Data Relevant to Course Designers. Journal of Learning Analytics, 1 (3), 223-243.

"low hanging fruit" and seek variables and questions that faculty identify as meaningful, and provide guidance for them with respect to course design.

To date, research in this area has started to explore very broad questions from a wide variety of perspectives, but with limited tools and data. For example, course management systems might track whether students download a particular reading, if they ask questions in online forums, or how much time they spend on certain online tasks (c.f., Ali et al., 2012; Macfadyen \& Dawson, 2010). In these cases, researchers are limited to the data available in the course management system they use or by restrictions imposed by top-down approaches to data collection (Buerck \& Mudigonda, 2014). Questions are therefore often driven by what data is easy to collect rather than what data is pedagogically meaningful. In fact, feedback from faculty about LOCO-Analyst revealed that most respondents did not find the information useful (Ali et al., 2012; Ferguson, 2012). A related problem is synthesizing the data in a way that will encourage faculty to use them (Ali et al., 2012) or creating a process that achieves buyin from relevant stakeholders (Buerck \& Mudigonda, 2014).

\subsection{Institutional Change}

Even with these tools and processes, implementing evidence-based educational practices requires careful planning and institutional self-reflection (Fixsen, Naoom, Blase, Friedman, \& Wallace, 2005). Individual departments or programs seeking to implement such change in order to demonstrate the worth of their curriculum may face considerable resistance from stakeholders, like faculty members. In order to overcome these challenges, we have chosen to follow empirically based principles of change, such as those outlined by Adrienne Kezar and others (Henderson et al., 2011; Kezar \& Eckel, 2002; Kezar, 2001; Lindquist, 1978). Kezar (2001) provides a detailed list of research-based principles of change. Some of these principles are beneficial attitudinal factors, like being open and aware of politics at the institution, and realizing that change is a disorderly process. Others detail concrete strategies that guide the process and goals, including engaging in organizational self-discovery, facilitating "interaction to develop new mental models and sense-making" (Kezar, 2001, p. 118), and creating a roadmap for strategic change (Kezar, 2001; Lindquist, 1978). These activities mirror change strategies laid out elsewhere, like engaging in a collaborative process, motivating a vision and mission, and developing support structures (Henderson et al., 2011; Kezar \& Eckel, 2002). Because institutional changes relating to the curriculum directly affect faculty members, they are an important group to incorporate into the change process. In fact, the American Sociological Association (2005) emphasizes the role of faculty in instituting changes suggested by the empirical assessment of the goals, and a recent study also found that 78 percent of university presidents believe that faculty should drive institutional change and innovation (Selingo, 2013). 
(2014). Connecting Analytics and Curriculum Design: Process and Outcomes of Building a Tool to Browse Data Relevant to Course Designers. Journal of Learning Analytics, 1 (3), 223-243.

\section{PLACE AND PROCESS}

As is increasingly the case across academia, the Center for Learning Innovation (CLI) within the University of Minnesota Rochester (UMR) is committed to bringing together faculty, IT (Information Technology), and administration to share data, knowledge, and resources in an effort to provide the best possible learning environment for students (Neuhauser, 2012; Neuhauser \& Weber, 2011). The characteristics and qualities of the environment in the CLI (our department) make it an ideal place to develop, test, and implement tools and processes prior to distribution of those tools to academic environments potentially too complex for the early stages of such endeavours. First, faculty from across a variety of disciplines are housed in one department, and all tenured/tenure-track faculty are required to do research on learning as part of their tenure and promotion requirements. As a result, faculty in our department, which contains members trained in literature, public health, sociology, biology, chemistry, mathematics, physics, and philosophy, are accustomed to discussing a variety of different disciplinary and cross-disciplinary indicators for assessment and research. In fact, we have already approved Institutional Review Board protocols (\#1008E87333; \#0908S71602) in place for human subjects research that includes collecting student grades and course work across all courses offered in our department. Second, much student data is already stored in relatively central locations. All instructors use our inhouse curriculum management system, iSEAL (intelligent System for Education, Assessment, and Learning), which contains student assignments and course grade books (University of Minnesota Rochester, n.d.). We are also fortunate that, as part of the University of Minnesota system, we have the ability to share and access assignments and activities stored within both Google Drive and Moodle. Finally, the small size of our faculty and general openness to sharing de-identified data means it would be relatively easy to solicit input from the faculty, and to test preliminary data analysis tools across a wide array of disciplines. Because of our highly integrated core curriculum, we can analyze how performance on specific assignments in a course correlates with another assignment in a different course.

Despite these strengths, our faculty are still challenged by the practical hurdles of compiling and exploring data from a variety of courses, surveys, and databases. We believe, in line with the tenants of institutional change, that one of the best ways to encourage faculty to connect analytics with course and curriculum design at our and other academic institutions is to create a process that allows faculty to identify variables that are significant and useful to them. Our ultimate goal is to facilitate faculty implementation of evidence-based course design. In line with principles of institutional change, a priority was to keep faculty at the centre of and driving the process.

After a variety of informal discussions with faculty in our department, the authors applied for and received an internal grant from the University of Minnesota Provost's Office (from the "Enhancement of Academic Programs Using Digital Technology" program) to develop a data-browsing tool. Following the receipt of that grant, our first step was to administer a survey and convene a focus group, run by the authors and attended by nine other tenure-track faculty in the department, to explore the types of 
(2014). Connecting Analytics and Curriculum Design: Process and Outcomes of Building a Tool to Browse Data Relevant to Course Designers. Journal of Learning Analytics, 1 (3), 223-243.

questions each faculty member was interested in exploring, and what kinds of data they would need to explore those questions. This survey and focus group allowed us to engage in self-discovery, as well as facilitate interaction and help all faculty members make sense of the goals of developing this tool (Kezar, 2001). In this focus group, faculty members outlined a list of indicators associated with pedagogical questions relevant to the evaluation and design of their courses. The faculty members also discussed the location (iSEAL, Moodle, Google Drive, admissions, student affairs, etc.) and accessibility of the data associated with each indicator. The authors then summarized and generated a list of questions with the associated indicators, and identified the potential mechanisms that could be used to allow them to access data through BoSCO. The authors then met to finalize the prioritized list as well as begin to discuss possible statistical tools that might be useful. The final prioritized questions, associated indicators, relevant databases, and suggested statistical tools were then used to build a mock-up of the learning analytics tool (BoSCO). In other words, instead of starting with the data and identifying questions to ask from there, we started with the research questions, and then sought to identify how to collate and browse the data in a way that allowed faculty to draw useful connections.

\section{OUTCOMES}

\subsection{Developmental Analytics}

The first outcome of our faculty-driven process was that we learned faculty believed data about student attitudes and affective traits were critical for their research on curriculum and curricular design. This type of data is exemplified by student developmental outcomes, like those adopted by the University of Minnesota (2011). Understanding the way students emotionally grow and develop during college is valuable to understanding curricular changes that could or should be made (Baxter Magolda, 2003; Oblinger, 2012a). As such, we suggest the addition of another category, developmental analytics, as a third subtype of analytics in the academic space (Figure 3). This concept is related to Buckingham Shum and Ferguson's (2012) Social Learning Analytics (SLA), but where SLA focuses on learning in a "participatory online culture," developmental analytics is broader, encompassing student experiences, skills, and affective and personality traits, both in and outside of the classroom. Using this type of analytics, researchers would gather and analyze data related to the development of students' dispositional traits and skills like curiosity, resilience, independence, interdependence, and selfawareness. Developmental analytics conceptually aligns administrative goals, learning outcomes, and developmental outcomes so that diverse types of data and analyses can be used by those engaging in course and curricular design.

The different types of analytics used in academic institutions (institutional, developmental, and learning) deal with some distinct types of information, but some of the information that falls within each category is shared. In fact, we argue that the information and analyses shared by each of the three subtypes would be extremely valuable to course and curriculum designers in their efforts to construct learning 
(2014). Connecting Analytics and Curriculum Design: Process and Outcomes of Building a Tool to Browse Data Relevant to Course Designers. Journal of Learning Analytics, 1 (3), 223-243.

environments that serve to increase student retention, teach specific content, and promote the development of soft-skills (Oblinger, 2012a).

Subtype of Academic Analytics

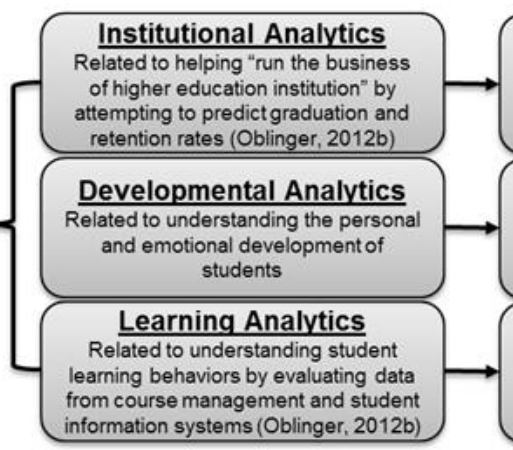

Examples of Data Used

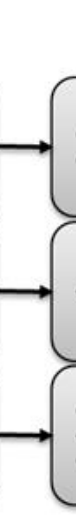

Student/faculty/staff demographic

Overall student GPA, entrance

exam scores

Student attitudes

Student mental health

Student activities outside the

classroom

Student progress toward learning outcomes

Assignment and assessments

Student performance, attendance
Level Goals

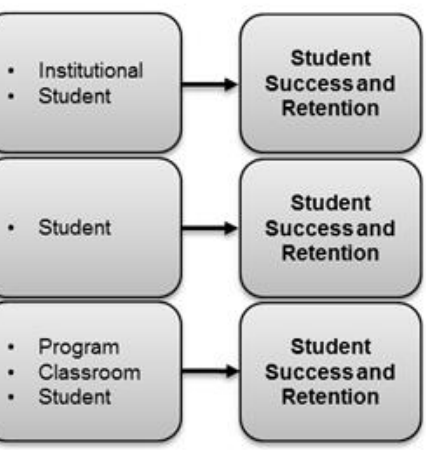

Figure 3. Models of subtypes of academic analytics with the inclusion of developmental analytics as a form of analytics, valuable conceptually and practically, for curriculum design.

\subsection{Browser of Student and Course Objects (BoSCO)}

Our interaction with faculty led us to believe that the best way to move forward once these variables were identified was to create a tool that allowed faculty a meaningful way to interact with student- and course-related data in a dynamic fashion. Based on faculty response to date, it is our hope that this interactive process - in which we facilitate faculty buy-in and include easy to use analysis tools in BoSCO - allows for a bridge to be built between the analytics space and the course/curriculum design environments (Figure 4). Specifically, our hope is that a tool that uses data defined as relevant by course and curricular designers will allow us and others to evolve from a model where data relevant to institutional and learning analytics exists but is largely unused by designers who default to a design model that replaces data with only course grades, intuition, and/or anecdote (Figure 4A). By incorporating data from developmental analytics and providing a tool to browse data from all three subtypes of academic analytics, it is hoped that our curricular designers and others can move to a design process that brings data analysis into the design process but does not eliminate the possibility of including information gathered by experience and/or intuition (Figure 4B). We also wanted to create a tool that was open and available, so that it could be useful to faculty members and departments at other campuses and institutions. 
(2014). Connecting Analytics and Curriculum Design: Process and Outcomes of Building a Tool to Browse Data Relevant to Course Designers. Journal of Learning Analytics, 1 (3), 223-243.

A)

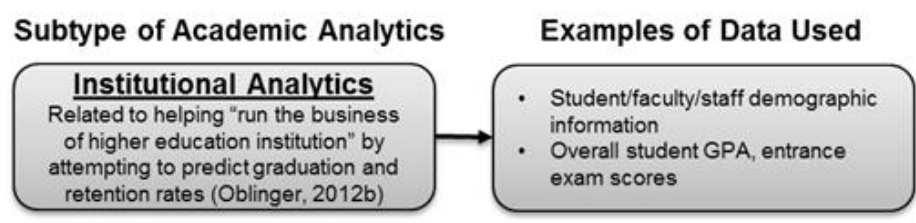
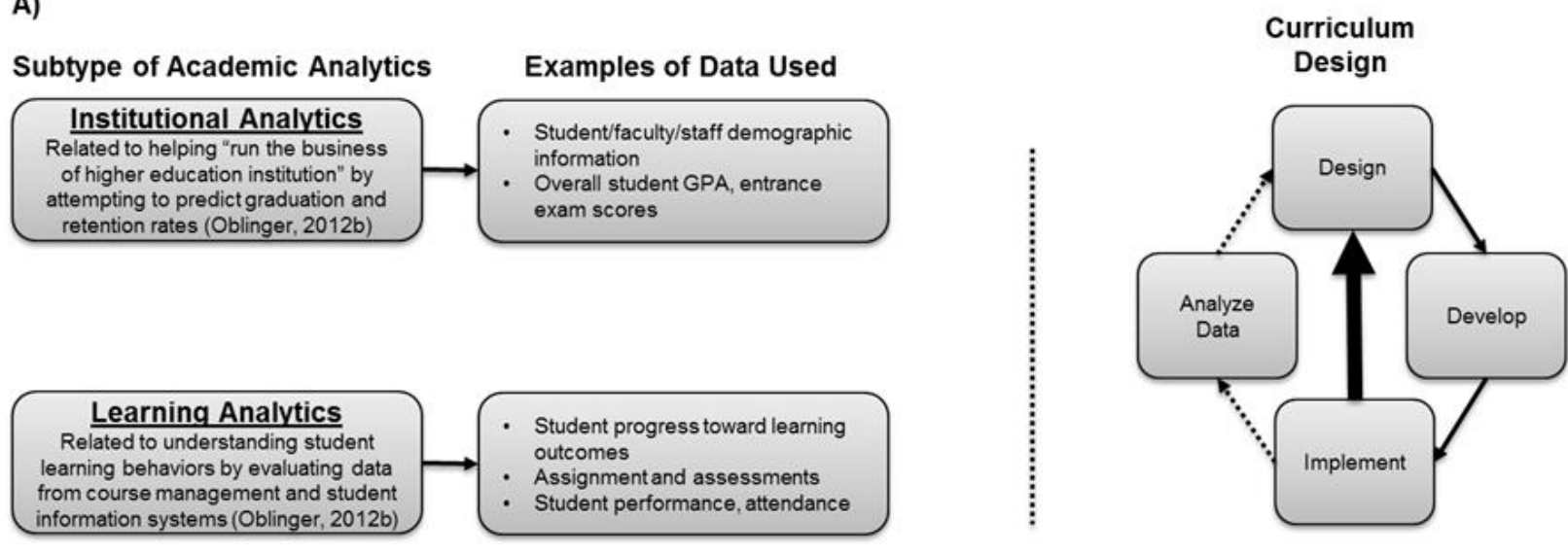

B)

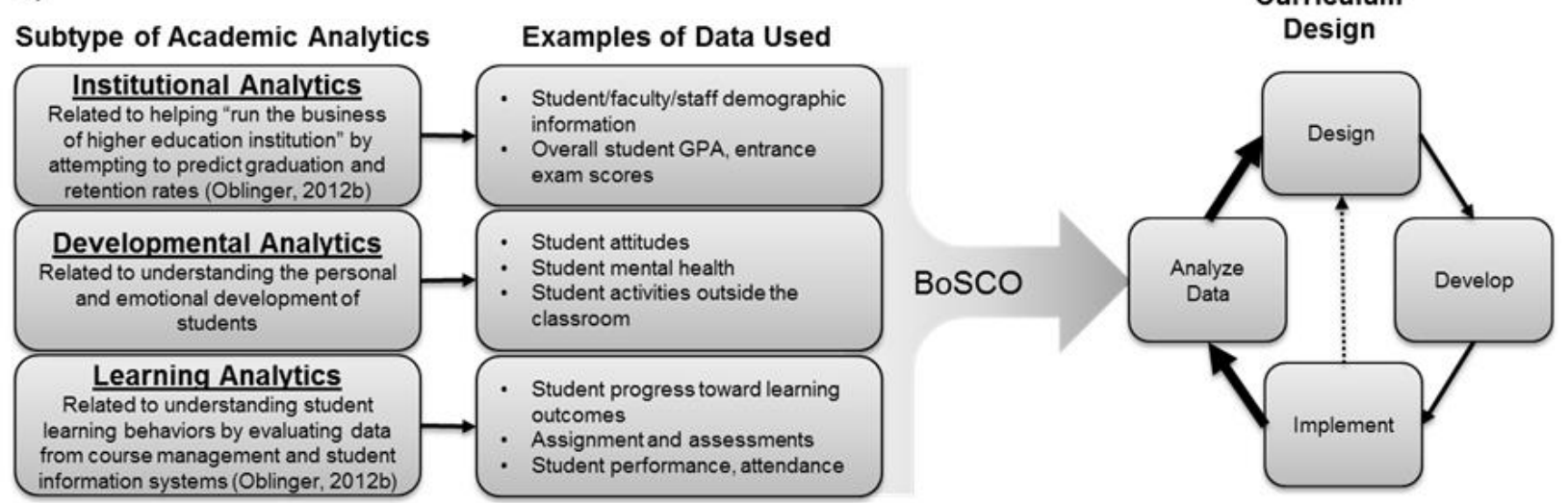

Figure 4. Schematic of the relationship between analytics and curriculum design.

A) Under the traditional curriculum design strategy and with current conceptual distinctions in analytics. Note the lack of connection between analytics and curriculum design, and the tendency to bypass rigorous data analysis in the design process as denoted by the large arrow between "Deliver" and "Design." B) A modified approach that incorporates developmental analytics and includes a more intentional use of quantitative data in the design process as denoted by larger arrows between "Implement," "Analyze Data," and "Design." Note that BoSCO is an example of a tool that bridges the analytics and design areas by facilitating the inclusion of relevant data and analyses to curriculum designers. 
(2014). Connecting Analytics and Curriculum Design: Process and Outcomes of Building a Tool to Browse Data Relevant to Course Designers. Journal of Learning Analytics, 1 (3), 223-243.

The information gathered from the faculty focus groups was first used to generate a conceptual model of the foundational components of the BoSCO tool (Figure 5). This model included the primary data sources that contained the types of information that the faculty found the most relevant, including the ability to explore survey data about student attitudes or other student-development-related information (Figure 5, lower left box). Also included in the model were the basic display, user interface, and analysis elements necessary to begin the build out of the project.

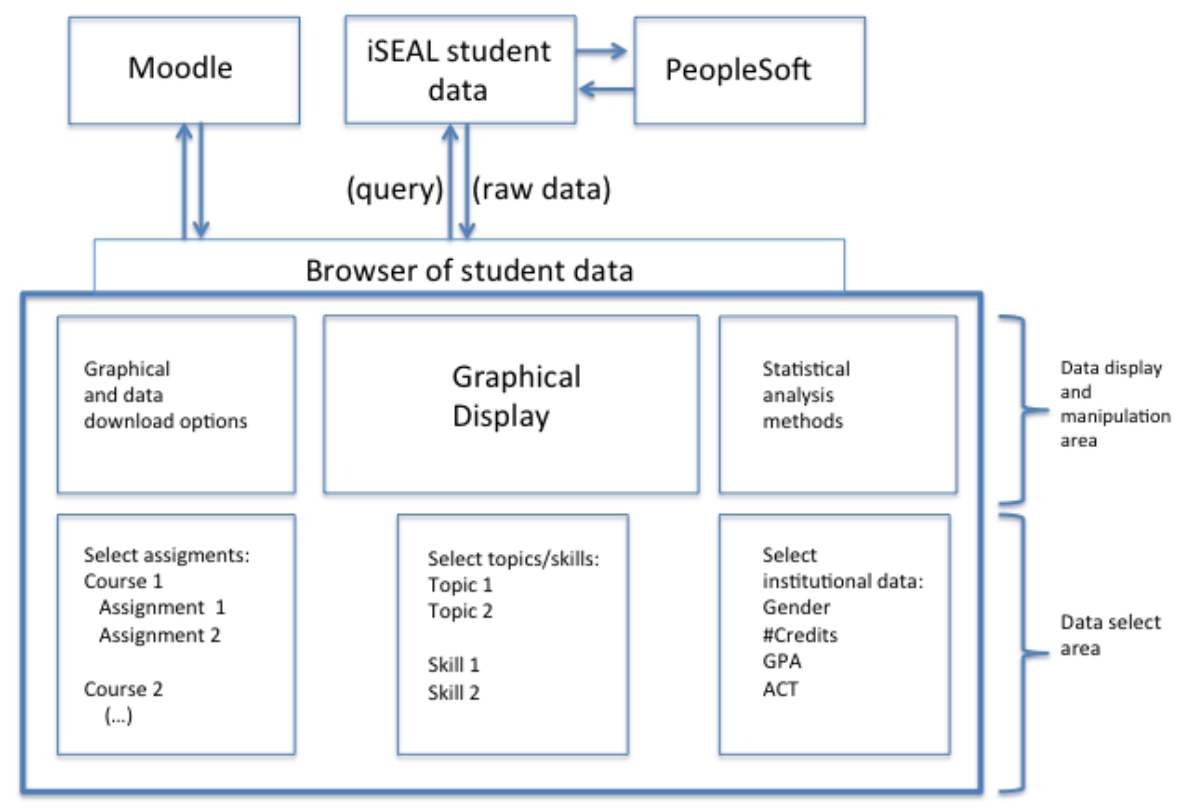

Figure 5. Conceptual model of BoSCO showing the basics of the graphical user interface as well as the specific data sources determined to be relevant based on faculty input.

The diverse types of data requested by faculty require that data input into BoSCO be uniform but flexible. To promote a uniform data structure, BoSCO requires comma separated value (.csv) files with a specific file format that can be generated automatically by downloading the files directly from iSEAL or manually by downloading a template .csv file and copying and pasting data into the template prior to uploading to BoSCO. To accommodate the need for flexibility, the current version of the tool includes an introductory window for uploading data in the form of "course," "student performance," and/or "demographic" .csv files. Permitting files to be uploaded manually allows the tool to be more flexible in that it means researchers can include data from outside of iSEAL. In the future, we plan to explore the possibility of downloading BoSCO formatted files directly from other learning management systems (e.g., Moodle) to reduce the need for manual formatting. Multiple course-performance data files can be uploaded into BoSCO, which can then be used to compare individual students' performance across multiple courses. 
(2014). Connecting Analytics and Curriculum Design: Process and Outcomes of Building a Tool to Browse Data Relevant to Course Designers. Journal of Learning Analytics, 1 (3), 223-243.

Permitting multiple types of data to be uploaded and explored by BoSCO also means that each faculty member uploading data is responsible for having the appropriate institutional access and, when required, Institutional Review Board (IRB) approval. Currently, student privacy and consent can be managed in two ways. In the first, the Course Management System that stores the student data also keeps the record of students who gave their consent under the appropriate IRB protocol. This is the strategy adopted in our department where iSEAL merges and filters the necessary data and de-identifies the students before faculty download the .csv files in BoSCO format. By doing so, faculty can combine several datasets belonging to different researchers without dealing with any identifiable data. A second way to manage privacy and consent is by individual faculty members manually de-identifying students in the dataset(s) associated with each of their courses and cross-referencing the students with a list of students who consented under the appropriate IRB protocol. Based on feedback from our faculty group, this second process is moderately useful for the basic browsing of individual courses but becomes very labour intensive when trying to align student lists across courses or with data collected outside of courses. In this case, the first approach is preferred. However, if data is not being used for research but just for internal quality control or curriculum design, in the U.S., no institutional review or consent is required.

The BoSCO web platform was designed as a lightweight client-side application that can run on any device. The web platform is a set of JavaScript libraries that read the files uploaded by the user and create a session-key. It does not call any third-party servers. Once the session is over, the user decides whether or not to save the session-key and the data associated to it. Because of its lightweight characteristics, rather than focusing on computationally demanding statistical analysis, BoSCO focuses on the browsing, filtering, and graphical display of data using JavaScript graphical libraries such as Flot (Laursen \& IOLA, 2013) and d3 (Bostock, 2013).

\subsection{How BoSCO can be used to Explore Data}

In order to bridge institutional, academic, and developmental analytics, our process indicates that faculty want a tool that goes beyond exploring de-identified grade books. In addition to exploring variables and relationships from the curricular level, through the course level, and down to the level of assignments, faculty wanted to be able to evaluate student performance in courses against other types of data, such as demographic information and attitudinal or survey data. In the short term, in order to make practical this type of data exploration, faculty can upload course grade books, survey, and other types of data into the current "beta" version of BoSCO. Once uploaded, the user can begin to explore the data from an assignment, course, or semester. In the longer term, we plan to automate this process so that users can employ BoSCO to upload data directly from common course management systems, like Moodle. 
(2014). Connecting Analytics and Curriculum Design: Process and Outcomes of Building a Tool to Browse Data Relevant to Course Designers. Journal of Learning Analytics, 1 (3), 223-243.

As shown in Figure 6, users can begin their exploration by evaluating relationships among a variety of variables with some basic statistics. The user can select a course-level analysis (Figure 6A), which permits a high-level view of how students are performing in one course relative to another $\left(R^{2}\right)$ and can include all courses in a given program. For the purpose of demonstration, we show the results of a comparison of final grades among two different biology courses (BIOL 2331, 2332: Anatomy and Physiology I, II), two different chemistry courses (CHEM 2331, 2333: General Chemistry I, II), and an introductory sociology course (SOC1571: Sociology) completed in 2011 and 2012 in our program. The semester-level analysis (Figure 6B) shows correlations in student performance in the same five courses over multiple semesters. The assignment-level shown in Figure $6 \mathrm{C}$ shows correlations in student performance on a variety of selected assignments completed in CHEM2331 and SOC 1571.

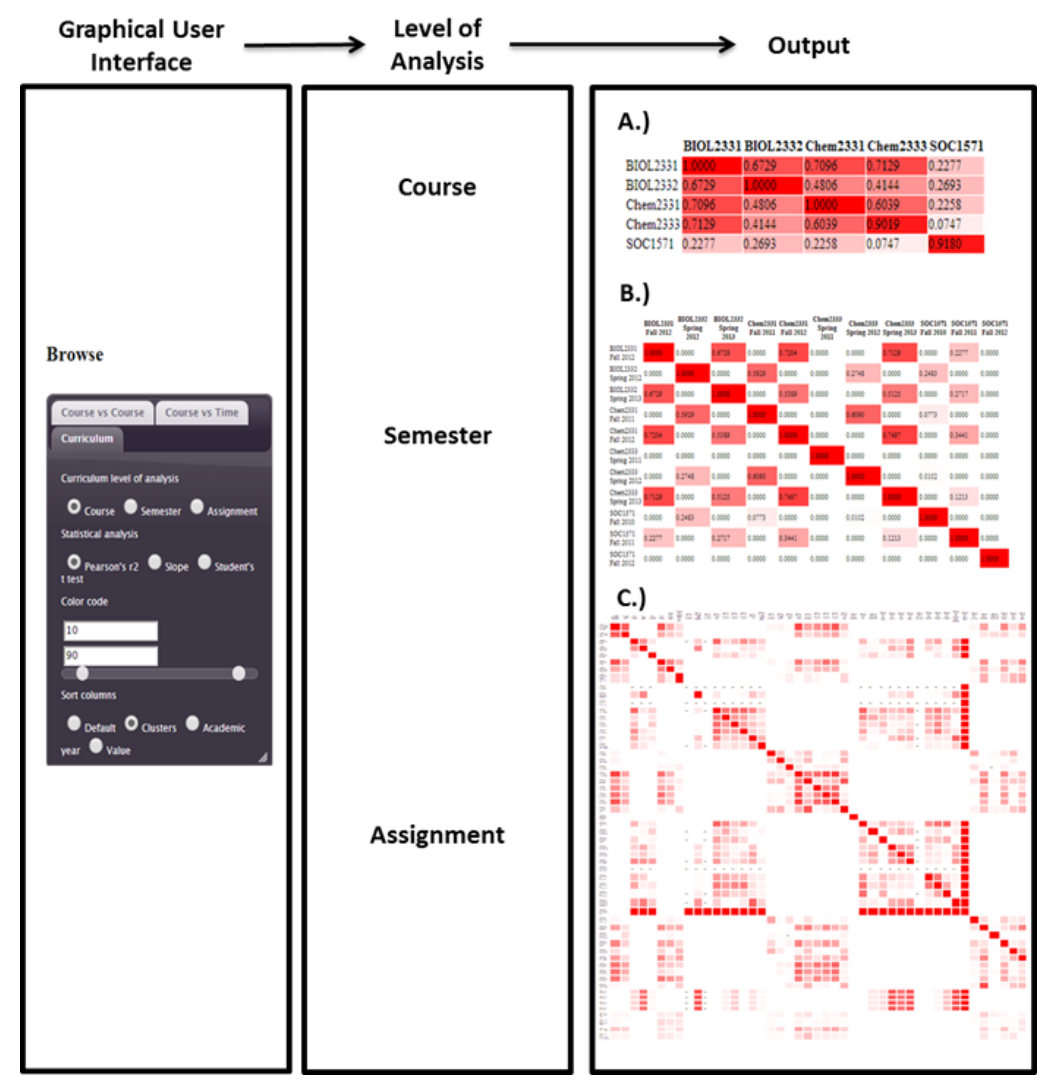

Figure 6: Sample analysis by level. This particular output shows $A$ ) a matrix of $R^{2}$ values for student course grades across 5 courses (BIOL 2331, 2332; CHEM 2331, 2333; SOC 1571), B) $R^{2}$ values for student course grades for the same 5 courses and across multiple semesters, and C) $R^{2}$ values for student grades on all assignments in CHEM 2331 and SOC 1571 in a single semester.

Should the user want to probe deeper than the big picture view offered by the analysis shown in Figure $6 \mathrm{~A}$, they can select (click) a specific cell in the correlation matrix, which then takes them to a different interface that permits exploration of variables in two specific courses. As shown in Figure 7, for example, 
(2014). Connecting Analytics and Curriculum Design: Process and Outcomes of Building a Tool to Browse Data Relevant to Course Designers.

clicking on the cell containing the $\mathrm{R}^{2}$ value calculated for SOC 1571 and CHEM 2331 allows the user to choose to view a bar chart or scatterplot of student performance with all students (no filter), or filtered by a variety of variables. In this case, the analysis filtered by sex shows only the final course grades for females enrolled in both courses, the analysis filtered by race shows only the final grades of students of colour. From here, the user can probe even deeper, by choosing specific assignments to compare using the filtered data. In this case, the assignment-level analysis shows the bar charts and scatterplots for a group paper assignment in sociology, and a homework quiz from chemistry.

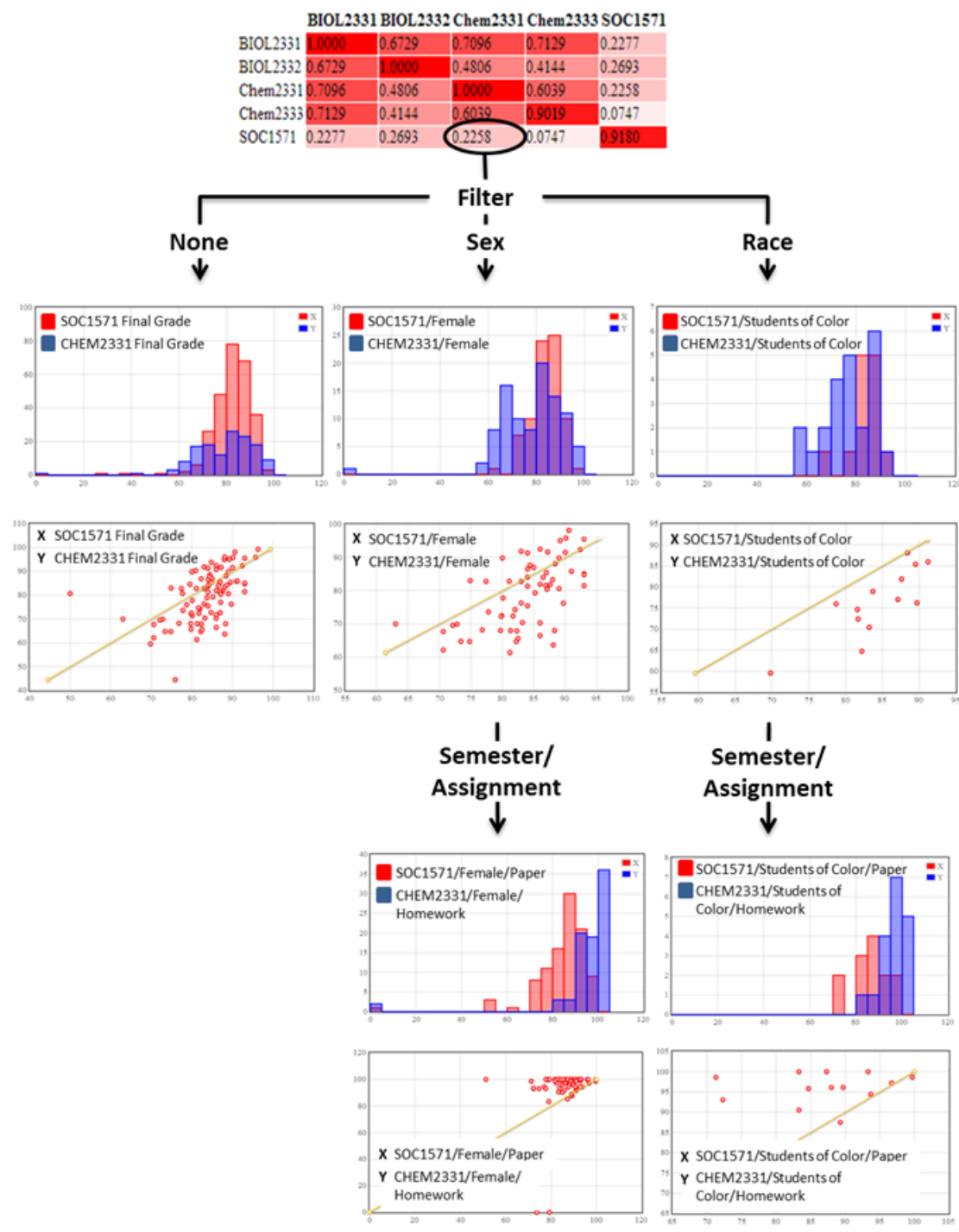

Figure 7. The user can further explore matrix results using bar charts or scatterplots, and filtering by demographic variables like sex or race, or filtering by specific assignments. The straight diagonal line in these scatterplots represents $x=y$, and can be used to compare whether students performed better in the $y$-axis category or the $x$-axis category. 
(2014). Connecting Analytics and Curriculum Design: Process and Outcomes of Building a Tool to Browse Data Relevant to Course Designers. Journal of Learning Analytics, 1 (3), 223-243.

This tool has the potential to be useful at the course, department, or program level to explore student success and retention. A faculty member or department head could identify courses or assignments that are challenging for all students, or for a subset of students. This tool could help answer a variety of questions: are students who take specific courses early in their college career more successful in the program? Are women, students of colour, or first-generation college students particularly likely to struggle with a specific course or set of assignments? Answers to these questions might guide advising, sequencing of required courses, or revision of assignments.

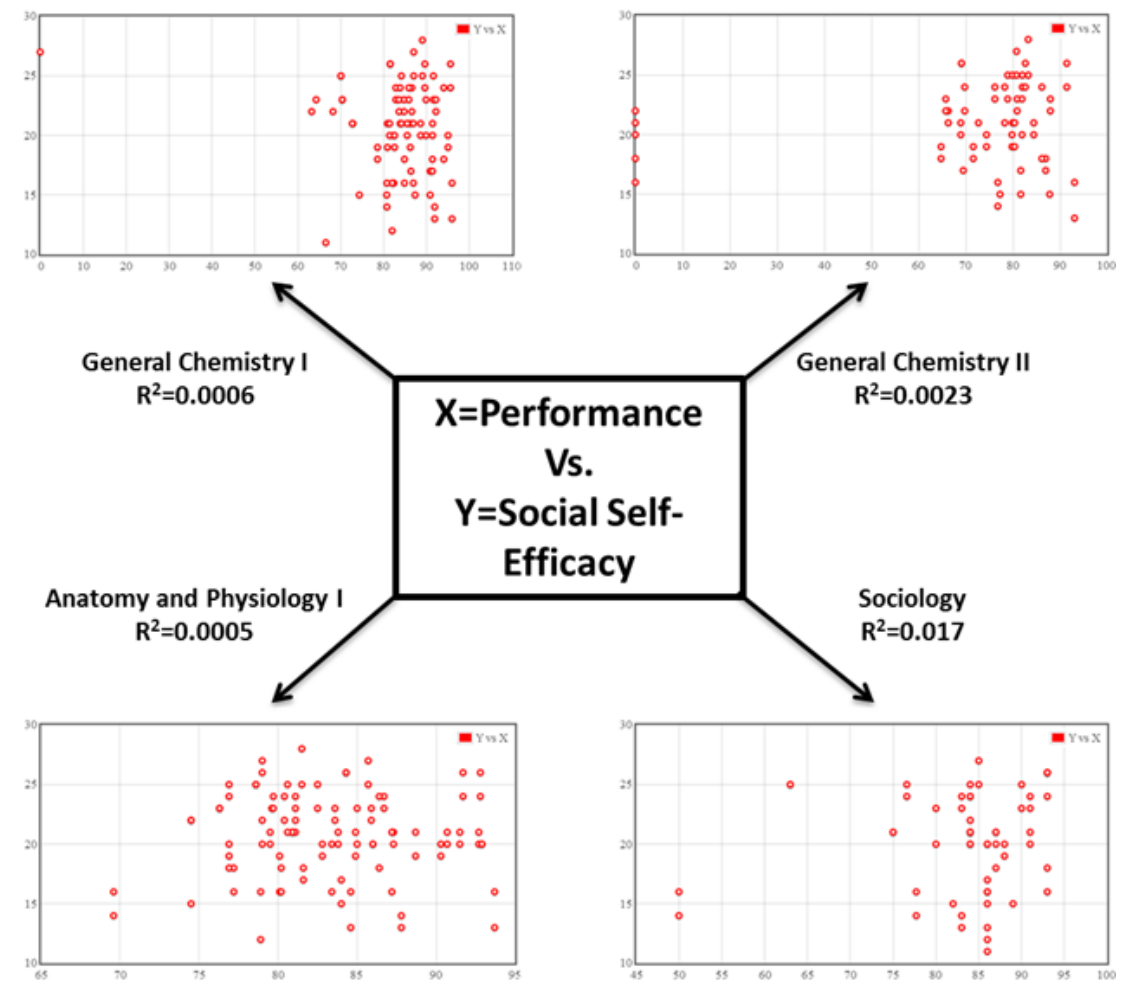

Figure 8. BoSCO outputs comparing survey and performance data. In this case, a cursory analysis indicates little correlation between students' social self-efficacy and final course grades in a variety of courses.

With the goal of making this tool useful for faculty, it was important that BoSCO have the additional capability of allowing the exploration of attitudinal or dispositional data along with course performance data (Figure 8). Exploring these types of data together can be extremely useful. In our degree program, for example, students engage in a significant amount of group work, the results of which may make up a large portion of their final course grade. While there is evidence to support this pedagogical approach (Johnson, Johnson, \& Stanne, 2000; Slavin, 1991), learning more about the relationship between course performance and how students rate their social self-efficacy could be very informative for supporting the model in our environment. Faculty here wanted to know whether requiring a significant amount of collaborative work is correlated with lower grades for students who were less outgoing, shyer, or with 
(2014). Connecting Analytics and Curriculum Design: Process and Outcomes of Building a Tool to Browse Data Relevant to Course Designers. Journal of Learning Analytics, 1 (3), 223-243.

lower self-efficacy in social settings; if so, then alterations in the pedagogical approach might be necessary.

To measure this personality characteristic, we needed data that fell outside the area of traditional course performance and closer to the area of student development. To that end, we looked to the work of Sherer et al. (1982), which supported the possibility of splitting the results of a self-efficacy assessment into two dimensions. One dimension is an indication of a global sense of self-confidence in a person's abilities to achieve future success, which Sherer et al. (1982) coined "general self-efficacy." The second dimension includes individuals' belief in their competence in social situations, or social selfefficacy (Sherer et al., 1982). Social self-efficacy has been found to be correlated with a perceived social regard, the likelihood of instigating interactions with others, and overall competence in social situations (Connolly, 1989). Therefore, after giving most of the students in our program a short social self-efficacy survey (consistent with approved IRB protocols), the data were uploaded to BoSCO. Using BoSCO, the user easily obtained $R^{2}$ and scatterplots to explore the correlation between social self-efficacy and final course grades in Anatomy and Physiology, General Chemistry I and II, and Sociology. In this case, $\mathrm{R}^{2}$ and a visual analysis of scatterplots indicate a low correlation between social self-efficacy and final course grades, which supports the use of collaborative learning strategies since they appear not to be harmful for those students with lower social self-efficacy. From this analysis, a combined data file that includes the data from a variety of sources can be downloaded for more in-depth and rigorous analysis in a statistical analysis package, but BoSCO allows for initial analyses that can inform these research questions.

\section{LIMITATIONS}

Though we have made significant progress in creating a process to encourage and facilitate integrating empirical evidence into course design and revision, there are limitations. Our process appears to be working well within our environment but we have a relatively small number of faculty within a unique educational environment. For example, as mentioned above, our tenure code requires tenured/tenure track faculty to engage in research on teaching and learning. What faculty wish to research here, their willingness to share data, and the time they are willing to expend doing that research, may be quite different from other departments. Therefore, identifying what data faculty want may be simpler here than in larger departments. However, there are many departments that face the problem of defending their worth and/or curriculum to administration or accreditors, and such a tool may be useful to them (U.S. Department of Education, 2000). Even with participation from all faculty, much work has to be done to develop communication pathways among different units of an institution in order to identify and access data, and to ask questions useful across the entire institution. This can be quite time consuming and is potentially fraught with a variety of political hurdles (Henderson et al., 2011; Buerck \& Mudigonda, 2014). 
(2014). Connecting Analytics and Curriculum Design: Process and Outcomes of Building a Tool to Browse Data Relevant to Course Designers. Journal of Learning Analytics, 1 (3), 223-243.

The tool that has emerged from our process also has significant limitations in its current form. Manually uploading spreadsheets is more labour intensive than is desirable in the long-term, but it does eliminate two problems. One, BoSCO does not have to deal with political problems regarding who owns the data being browsed. As the one compiling the spreadsheets, the researcher and their collaborator(s) are responsible for complying with IRB and FERPA regulations. Two, because it does not need to connect to any particular server to download data, BoSCO works with any Course Management System. As long as the data being uploaded are in the right format, BoSCO can browse them. Furthermore, BoSCO is intended to be a way to explore data and not a robust quantitative data analysis tool. To gain more analysis strength we are designing BoSCO to give users the ability to download data in formats commonly used by quantitative analysis software, like R or SPSS.

\section{CONCLUSION}

As those in academia push forward in pursuit of discovering the most effective ways to inform best practices, it is imperative that processes and tools are developed that permit curriculum designers to acquire and explore data relevant to student learning, development, and retention. Such tools would also be extremely useful to departments seeking to present evidence of a quality program to administrators, accreditors, and others. To innovate, institutions must expand beyond relatively narrow analyses and incorporate diverse datasets from across the institution to provide a more holistic vision of students. In other words, students exist outside the classroom, and understanding the "whole student" - inside and outside the classroom - provides us with a more complex and complete picture of student performance. While many institutions have begun to require teachers in higher education to provide data regarding the learning that takes place in their classrooms, these datasets provide an incomplete picture of student success. Institutions of higher education need to build structures that facilitate communication across the institution to permit curriculum designers access to data that would complement the data they already have on student performance in the classroom. With a more complete picture, faculty and administrators have a stronger foundation from which to innovate in terms of both educational strategies, and ways to explore and document a variety of factors that affect student learning, development, and retention.

In most places of higher education, integrating evidence-based practices involves a change from the norm. The literature on institutional change offers some effective and empirically based strategies to alter educational practices effectively. At our institution, our process has led to us to identify two needs, both articulated by faculty. First is the need to add developmental analytics to institutional and learning analytics as subtypes of academic analytics, and second, faculty need to have a tool to explore the data associated with all three subtypes of academic analytics. If designed and developed properly, with appropriate input from stakeholders, it is our belief that these or similar tools and processes can facilitate asking and answering questions that designers, instructors, and administrators have about student achievement across an entire curriculum. 
(2014). Connecting Analytics and Curriculum Design: Process and Outcomes of Building a Tool to Browse Data Relevant to Course Designers. Journal of Learning Analytics, 1 (3), 223-243.

It is not our intention for BoSCO to be an end in itself. Just as narrow analyses focusing on only one slice of a student's experience in an institution is unlikely to yield data that can guide institutional change, one tool cannot be the solution to all institutional problems. Because BoSCO was developed by faculty to help them explore their research questions, its strength lies in its flexibility to incorporate data from a variety of sources and provide a way to begin exploring the data. BoSCO would be a first step, a place where faculty and others could begin to explore data in an intuitive way, begin to ask questions, and begin to understand how a variety of disparate data sets do or do not fit together into a whole. Because it was designed to start with questions and not specific data, the driving force will always be the creative vision of the user. BoSCO is a lens that helps the user understand both the big picture, and the way that subsets of students fit within that bigger picture.

Forming a functional connection between analytics and curriculum design is a complicated and daunting endeavour made more challenging by the continuous growth of data available to curriculum designers. Awareness of the existence of the data is not enough. To draw useful conclusions about what data is or is not correlated with best practices, curricular designers need tools that allow them to navigate and explore the ever-growing space of usable data in the way a telescope is used to explore celestial objects. However, unlike space, data is not continuous, nor are all datasets equally relevant to the curriculum designer or education researcher. These tools should allow interested designers and researchers the opportunity to navigate relevant datasets intentionally, categorize elements within those datasets, and inform hypotheses that can be assessed quantitatively and validated with subsequent observations. While we have just begun to use BoSCO and the direct impact on curricular design has yet to be fully realized, we have made progress developing a tool that designers will eventually use to inform an iterative curricular design process with a more evidenced-based view of factors related to student success and retention.

\section{REFERENCES}

Ali, L., Hatala, M., Gašević, D., \& Jovanović, J. (2012). A qualitative evaluation of evolution of a learning analytics tool. Computers \& Education, 58(1), 470-489. doi:10.1016/j.compedu.2011.08.030

American Sociological Association. (2005). Creating an effective assessment plan for the sociology major. Washington, D.C.: American Sociological Association.

Antonio, A. L. (2004). The influence of friendship groups on intellectual self-confidence and educational aspirations in college. The Journal of Higher Education, 57(4), 446-471.

Baxter Magolda, M. B. (2003). Identity and learning: Student affairs' role in transforming higher education. Journal of College Student Development, 44(2), 231-247.

Bostock, M. (2013). Data-driven documents. Retrieved 19 December 2013, from http://d3js.org/

Boyer Commission on Educating Undergraduates in the Research University. (1998). Reinventing undergraduate education: A blueprint for America's research universities. Retrieved from http://www.eric.ed.gov/ERICWebPortal/detail?accno=ED424840 
(2014). Connecting Analytics and Curriculum Design: Process and Outcomes of Building a Tool to Browse Data Relevant to Course Designers. Journal of Learning Analytics, 1 (3), 223-243.

Buckingham Shum, S., \& Ferguson, R. (2012). Social learning analytics. Educational Technology \& Society, 15(3), 3-26.

Buerck, J. P., \& Mudigonda, S. P. (2014). A resource-constrained approach to implementing analytics in an institution of higher education: An experience report. Journal of Learning Analytics, 1(1), 129-139.

Connolly, J. (1989). Social self-efficacy in adolescence: Relations with self-concept, social adjustment, and mental health. Canadian Journal of Behavioural Science, 21(3), 258-269. doi:10.1037/h0079809

Executive Office of the President's Council of Economic Advisers. (2009). Preparing the workers of today for the jobs of tomorrow. Retrieved from http://www.whitehouse.gov/administration/eop/cea/Jobs-of-the-Future

Ferguson, R. (2012). Learning analytics: Drivers, developments and challenges. International Journal of Technology Enhanced Learning, 4(5/6), 304. doi:10.1504/IJTEL.2012.051816

Fixsen, D. L., Naoom, S. F., Blase, K. A., Friedman, R. M., \& Wallace, F. (2005). Implementation research: A synthesis of the literature. Retrieved from http://centerforchildwelfare2.fmhi.usf.edu/kb/Implementation/Implementation\%20Research\% 20-\%20A\%20Synthesis\%20of\%20Literature\%20\%20-\%202005.pdf

Handelsman, J., Miller, S., \& Pfund, C. (2007). Scientific teaching. New York: W. H. Freeman.

Henderson, C., Beach, A., \& Finkelstein, N. (2011). Facilitating change in undergraduate STEM instructional practices: An analytic review of the literature. Journal of Research in Science Teaching, 48(8), 952-984. doi:10.1002/tea.20439

Johnson, D., Johnson, R., \& Stanne, M. B. (2000). Cooperative learning methods: A meta-analysis. Cooperative Learning Center, University of Minnesota. Retrieved from http://www.cooperation.org/pages/cl-methods.html.

Kezar, A., \& Eckel, P. (2002). Examining the institutional transformation process: The importance of sensemaking, interrelated strategies, and balance. Research in Higher Education, 43(3), 295328.

Kezar, A. J. (2001). Understanding and facilitating organizational change in the 21st century: Recent research and conceptualizations. San Francisco: Jossey-Bass.

Labov, J. B., Singer, S. R., George, M. D., Schweingruber, H. A., \& Hilton, M. L. (2009). Effective practices in undergraduate STEM education part 1: Examining the evidence. CBE Life Science Education 8, 157-161.

Laursen, O., \& IOLA. (2013). Flot. Retrieved from http://www.flotcharts.org/ Lindquist, J. (1978). Strategies for change. Berkeley, CA: Pacific Soundings Press.

Macfadyen, L. P., \& Dawson, S. (2010). Mining LMS data to develop an "early warning system" for educators: A proof of concept. Computers \& Education, 54(2), 588-599.

Molenda, M. (2003). In search of the elusive ADDIE model. Performance Improvement, 42(5), 34-36.

Morris, L. V., Finnegan, C., \& Wu, S.-S. (2005). Tracking student behavior, persistence, and achievement in online courses. Internet and Higher Education, 8, 221-231. 
(2014). Connecting Analytics and Curriculum Design: Process and Outcomes of Building a Tool to Browse Data Relevant to Course Designers. Journal of Learning Analytics, 1 (3), 223-243.

National Research Council. (1996). From analysis to action: Undergraduate education in science, mathematics, engineering, and technology. Retrieved from http://www.nap.edu/catalog.php?record_id=9128

National Science Foundation. (1996). Shaping the future: New expectations for undergraduate education in science, mathematics, engineering, and technology: Executive summary of its review of undergraduate education. Retrieved from http://www.nsf.gov/pubs/stis1996/nsf96139/nsf96139.txt

Neuhauser, C. (2012). From academic analytics to individualized education. In A. Hill Duin et al. (Eds.), Cultivating change in the academy: 50+ stories from the digital frontlines at the University of Minnesota in 2012. University of Minnesota. Retrieved from https://cultivatingchange.wp.d.umn.edu/from-academic-analytics/

Neuhauser, C., \& Weber, K. (2011). The student success coach. New Directions for Higher Education, 153, 43-52. doi:10.1002/he.425

Oblinger, D. G. (2012a). Analytics: What we're hearing. EDUCAUSE Review, 47(6). Retrieved from http://www.educause.edu/ero/article/analytics-what-were-hearing

Oblinger, D. G. (2012b). Let's talk ... analytics. EDUCAUSE Review, 47(4). Retrieved from http://www.educause.edu/ero/article/lets-talk-analytics

Selingo, J. J. (2013). Attitudes on innovation: How college leaders and faculty see key issues facing higher education. Chronicle of Higher Education. Retrieved from http://images.results.chronicle.com/Web/TheChronicleofHigherEducation/\%7B1bcc7646-4c084121-88f5-20addba642c0\%7D_innovationsurvey_adobe.pdf

Severiens, S. E., and Schmidt, H. G. (2009). Academic and social integration and study progress in problem based learning. Higher Education, 58, 59-69. doi: 10.1007/s10734-008-9181-x

Sherer, M., Maddux, J. E., Mercandante, B., Prentice-Dunn, S., Jacobs, B., \& Rogers, R. W. (1982). The self-efficacy scale: Construction and validation. Psychological Reports, 51(2), 663-671. doi:10.2466/pr0.1982.51.2.663

Siemens, G., \& Long, P. D. (2011) Penetrating the fog: Analytics in learning and education. Educause Review Online. Retrieved from http://www.educause.edu/ero/article/penetrating-fog-analyticslearning-and-education

Slavin, R. E. (1991). Synthesis of research of cooperative learning. Educational Leadership, 48(5), 71-82.

Tinto, V. (1997). Classrooms as communities: Exploring the educational character of student persistence. Journal of Higher Education, 68(6), 599-623.

University of Minnesota. (2011). Student development outcomes. Retrieved from http://www.sdo.umn.edu/Students/Outcomes/index.html

University of Minnesota Rochester. (n.d.). iSEAL: intelligent System for Education, Assessment, and Learning. Retrieved 18 December 2013, from http://r.umn.edu/campus-resources/it/websupport/iseal/

U.S. Department of Education. National Center for Education Statistics. (2000). The NPEC sourcebook on assessment definitions and assessment methods for critical thinking, problem solving, and writing. (Report No. NCES-2000-195) by T. Dary Erwin for the Council of the National 


\section{JOURNAL OF LEARNING ANALYTICS}

(2014). Connecting Analytics and Curriculum Design: Process and Outcomes of Building a Tool to Browse Data Relevant to Course Designers. Journal of Learning Analytics, 1 (3), 223-243.

Postsecondary Education Cooperative Student Outcomes Pilot Working Group: Cognitive and Intellectual Development. Washington, D.C.: U.S. Department of Education. 